\title{
Microalgal biomass as renewable biofiller in natural rubber compounds
}

\author{
Emanuela Bellinetto ${ }^{1}$ (D) Riccardo Ciapponi ${ }^{1,2}$ (D) Marco Contino ${ }^{1}$ (i) . \\ Claudia Marano ${ }^{1}\left[\mathbb{D}^{1} \cdot\right.$ Stefano Turri $^{1,2}{ }^{\mathbb{D}}$
}

Received: 26 July 2021 / Revised: 26 July 2021 / Accepted: 3 October 2021 /

Published online: 18 October 2021

(C) The Author(s) 2021

\begin{abstract}
Microalgal biomasses, consisting of micronized Spirulina Platensis and its low protein fraction, were investigated in this work as possible renewable biofillers in natural rubber compounds, with the aim of replacing the commonly used carbon black. Natural rubber, in some cases blended with $10 \%$ of epoxidized natural rubber to improve the matrix-filler affinity, was compounded with 25, 35, 50 and $75 \mathrm{phr}$ of each biomass. Compounds with 25, 35 and 50 phr of carbon black N990 were also prepared as benchmarks. After compounding, vulcanization times were determined by dynamic mechanical analysis. Rubbers were vulcanized by compression moulding and characterized by means of morphological analysis (scanning electron microscopy), thermal analysis (thermogravimetric analysis, dynamic mechanical thermal analysis) and mechanical tests (tensile tests, strain induced crystallization detection by X-ray diffraction, pure shear fracture tests). Microalgal biomass turned out to be homogeneously dispersed in natural rubber matrix and the materials obtained required lower curing times compared to carbon black compounds. It was found that, up to $50 \mathrm{phr}$, Spirulina has the ability to increase rubber tensile strength and modulus, acting similarly to N990, while decreasing rubber thermal stability and fracture toughness.
\end{abstract}

\section{Introduction}

Natural rubber (cis-1,4-polyisoprene) is one of the most important polymers naturally produced by plants, used in more than 40000 products. Its high performance features include resilience, elasticity, abrasion resistance, efficient heat dispersion

Emanuela Bellinetto

emanuela.bellinetto@polimi.it

1 Dipartimento di Chimica, Materiali e Ingegneria Chimica "Giulio Natta", Politecnico di Milano, Piazza Leonardo Da Vinci 32, 20133 Milano, Italy

2 INSTM - Consorzio Interuniversitario Nazionale per la Scienza e Tecnologia dei Materiali, Via Giuseppe Giusti 9, 50121 Firenze, Italy 
and impact resistance [1]. Although these numerous outstanding characteristics, a wide variety of particulate fillers are necessarily used in the rubber industry for mechanical reinforcement, to reduce the material costs or to improve the rubber processing [2].

Being natural rubber a biobased polymer, the use of bio-reinforcements in substitution of non-renewable filler, as the widely used carbon black, is beneficial in the development of fully biobased and green materials, based on $100 \%$ renewable carbon [3]. The production of carbon black involves the vaporization of a heavy aromatic hydrocarbon feedstock, sprayed into a flame, that generates small molecular fragments able to recombine in aciniform carbon aerosol. Polynuclear aromatic hydrocarbons $(\mathrm{PAH})$ are inevitable by-products of this process. These molecules constitute particulate emissions that can be extremely dangerous for both the environment and human health $[4,5]$.

Different studies were carried out to explore the possibility of a partial or complete replacement of carbon black with more sustainable fillers. For example, using nano-whiskers isolated from bamboo waste, oil palm ash, lignin, waxy maize starch nanocrystal and chitosan [3, 6-9].

In this work the suitability of microalgal biomass as natural rubber biofiller has been studied. Microalgae and cyanobacteria are photosynthetic microorganisms that can grow rapidly and live in harsh conditions due to their simple multicellular structure. They obtain nutrients from the aquatic habitats, capture $\mathrm{CO}_{2}$ from the air and produce about $50 \%$ of the atmospheric oxygen. Thanks to their efficient biological system, able to use sunlight to produce organic compounds, they are rich in proteins, lipids and carbohydrates. These unique features make microalgae and cyanobacteria a potential renewable source promising for different commercial applications as biofuel production, wastewater treatment and $\mathrm{CO}_{2}$ mitigation, nutrition, cosmetic products, high-value compounds, pigments, biofertilizers or synthesis of antimicrobial drugs $[10,11]$.

Among these applications, microalgae were already adopted as fillers in various biobased polymers as PLA, pea protein/k-carrageenan/starch and gluten [12-18]. In particular, as concerns natural rubber, Glowinska et al. found that the addition of 10-30 phr of Spirulina led to a reduction of both its tensile strength and maximum strain [19]. These results could be associated to the large size of Spirulina particles employed, ranging from $14 \mu \mathrm{m}$ to $134 \mu \mathrm{m}$. In view of this, in the present work, Spirulina Platensis and a low-protein fraction of Spirulina Platensis (extracted to preserve the protein moiety for other purposes, as animal feeding) were first subjected to size reduction through a ball-milling procedure and then, up to $75 \mathrm{phr}$, compounded with natural rubber. The influence of microalgal biomass on rubber curing kinetics, morphology, thermal stability, tensile behaviour, strain induced crystallization and fracture toughness was investigated, and the environmental burden of carbon black production compared to microalgal biomass cultivation was briefly discussed.

The microalgal biomass used in this work was cultivated in treating wastewater of a diary, in the framework of the European Project "SaltGae". In this context microalgae culture provides tertiary and quaternary biotreatments of wastewater, removing organic ions, especially $\mathrm{N}$ and $\mathrm{P}$, and heavy metals, and reduces the biochemical 
oxygen demand (BOD) from water [18, 20-23]. Exploiting microalgae as fillers, after the purification processes, means further valorising the algal biomass generating a resource instead of a waste [18].

\section{Materials and methods}

Standard Malaysian natural rubber CV60 (NR) was supplied by Cerisie S.r.l. while Epoxyprene 50 (ER), natural rubber with an epoxidation level equal to 50\%, was supplied by Manuli Rubber Industries S.p.a.

Sulphur super ventilated (S), used as vulcanizing agent, was provided by Schiavi Luigi Polverizzazione Minerali (Milan, Italy). Zinc oxide ( $\mathrm{ZnO}$ ), stearic acid (SA) and 2-mercaptobenzothiazole (MBT) were purchased from Sigma-Aldrich. ZnO and SA worked as activator agents in vulcanization process, while MBT acted as an accelerant.

Lyophilized Spirulina Platensis biomass (SPI), tested as natural rubber biofiller, was supplied by Archimede Ricerche S.r.l. (Imperia, Italy). In Table 1 composition expressed in percentage on dry matter, that is $97,49 \%$ of the total biomass, is reported.

Part of Spirulina Platensis biomass was treated by Extractis (Dury, France) that, by solubilization and centrifugation, extracted part of proteins from the microalgal biomass. The obtained residue of Spirulina Platensis (SPR), characterized by $36 \%$ of proteins, was also tested as rubber biofiller.

Carbon black N990 (CB N990), having particles size of $280 \mathrm{~nm}$ diameter, was supplied by Carbocrom S.r.l. and used as filler benchmark.

\section{Rubber compounds preparation}

Before being compounded with NR, microalgal biomasses have been ground by ball milling, using zirconia spheres, for $24 \mathrm{~h}$, in order to reduce the size of the aggregates. Scanning electron microscope EVO 50 Extended Pressure (Zeiss) was used to determine the size and morphology of microalgal particles obtained after milling procedure.

Rubber compounds were then prepared in Brabender internal mixer R Lab Station 7 with Roller Mixer W50 at $55{ }^{\circ} \mathrm{C}$ and $80 \mathrm{rpm}$. Mixing process was carried out in two steps, preventing compound overheating and vulcanization in the

Table 1 Composition of Spirulina Platensis $(\% /$ $\mathrm{DM}=$ percentage on dry matter)

\begin{tabular}{lc}
\hline Constituents & $\% / \mathrm{DM}$ \\
\hline Ash & 9.12 \\
Proteins & 67.78 \\
Sugars & 9.31 \\
Free Sugars & 2.79 \\
Lipids & 6.26 \\
\hline
\end{tabular}


instrument. In the first step NR, in some cases with the addition of ER, was mixed with the selected filler: microalgal biomass or carbon black. In the second step $\mathrm{ZnO}, \mathrm{SA}, \mathrm{S}$ and MBT were added in this order. Mixing process continued until reaching a plateau in torque-time curve. In Table 2 components of each rubber compound are reported.

To determine the vulcanization time at $150{ }^{\circ} \mathrm{C}$, Dynamic Mechanical Analysis (DMA) were performed with a Mettler Toledo DMA/SDTA 861e on $6 \mathrm{~mm}$ discs of each batch, in shear configuration, at $1 \mathrm{~Hz}$. Rubbers were then vulcanized in a hydraulic press (JBT Engineering) at $150{ }^{\circ} \mathrm{C}$ and 150 bar into $1 \mathrm{~mm}$ thick sheets and specimens (see "Rubber compounds characterization" section for further details).

\section{Rubber compounds characterization}

Scanning electron microscopy (SEM) was also used to study the morphology, the filler distribution in the matrix and the microalgal biomass/rubber matrix interface of NR SPI 35 and NR SPR 35. For every compound analysed, two specimens were produced and cold fractured in liquid nitrogen. The first sample was observed without any chemical modification of the surface, while the second was etched in a $\mathrm{NaOH}$ aqueous solution, having $\mathrm{pH}=10$, to remove the microalgal filler and to observe the empty cavities left in the rubber matrix.

Dynamic Mechanical Thermal Analysis (DMTA) were performed on vulcanized rubbers to determine their glass transition temperatures, in temperature scan from $-100{ }^{\circ} \mathrm{C}$ to $100{ }^{\circ} \mathrm{C}$, at $4{ }^{\circ} \mathrm{C} / \mathrm{min}$ and $1 \mathrm{~Hz}$.

Table 2 Composition of rubber compounds ( $\mathrm{phr}=$ parts in weight per hundred parts of rubber)

\begin{tabular}{|c|c|c|c|c|c|c|c|c|}
\hline \multirow[t]{2}{*}{ Sample Code } & \multirow{2}{*}{$\begin{array}{l}\text { NR } \\
\%\end{array}$} & \multirow{2}{*}{$\begin{array}{l}\text { ER } \\
\%\end{array}$} & \multicolumn{2}{|l|}{ Filler } & \multirow{2}{*}{$\begin{array}{l}\mathrm{S} \\
\mathrm{phr}\end{array}$} & \multirow{2}{*}{$\begin{array}{l}\mathrm{ZnO} \\
\mathrm{phr}\end{array}$} & \multirow{2}{*}{$\begin{array}{l}\text { SA } \\
\text { phr }\end{array}$} & \multirow{2}{*}{$\begin{array}{l}\text { MBT } \\
\text { phr }\end{array}$} \\
\hline & & & Name & $\mathrm{phr}$ & & & & \\
\hline NR 0 & 100.00 & - & - & - & 2.25 & 5.00 & 2.00 & 1.00 \\
\hline NR SPI 25 & 100.00 & - & Spirulina Biomass & 25.00 & 2.25 & 5.00 & 2.00 & 1.00 \\
\hline NR SPI 35 & 100.00 & - & & 35.00 & 2.25 & 5.00 & 2.00 & 1.00 \\
\hline NR SPI 50 & 100.00 & - & & 50.00 & 2.25 & 5.00 & 2.00 & 1.00 \\
\hline NR SPI 75 & 100.00 & - & & 75.00 & 2.25 & 5.00 & 2.00 & 1.00 \\
\hline NRER SPI 25 & 90.00 & 10.00 & & 25.00 & 2.25 & 5.00 & 2.00 & 1.00 \\
\hline NRER SPI 75 & 90.00 & 10.00 & & 75.00 & 2.25 & 5.00 & 2.00 & 1.00 \\
\hline NR SPR 25 & 100.00 & - & Spirulina Residue Biomass & 25.00 & 2.25 & 5.00 & 2.00 & 1.00 \\
\hline NR SPR 35 & 100.00 & - & & 35.00 & 2.25 & 5.00 & 2.00 & 1.00 \\
\hline NR SPR 50 & 100.00 & - & & 50.00 & 2.25 & 5.00 & 2.00 & 1.00 \\
\hline NR SPR 75 & 100.00 & - & & 75.00 & 2.25 & 5.00 & 2.00 & 1.00 \\
\hline NR N990 25 & 100.00 & - & Carbon Black N990 & 25.00 & 2.25 & 5.00 & 2.00 & 1.00 \\
\hline NR N990 35 & 100.00 & - & & 35.00 & 2.25 & 5.00 & 2.00 & 1.00 \\
\hline NR N990 50 & 100.00 & - & & 50.00 & 2.25 & 5.00 & 2.00 & 1.00 \\
\hline
\end{tabular}


Thermogravimetric analysis (TGA), to assess rubbers thermal stability, were executed using a TGA Q 500 (TA Instruments) from room temperature to $800{ }^{\circ} \mathrm{C}$, with a constant heating rate of $20^{\circ} \mathrm{C} / \mathrm{min}$, in air atmosphere.

Uniaxial tensile tests were performed on $1 \mathrm{~mm}$ thick dumbbell-shaped specimens, shown in Fig. 1, cut from $10 \mathrm{~cm} \times 10 \mathrm{~cm}$ sheets, using a Zwick/Roell BT-FR010TH. A50 dynamometer equipped with a $10 \mathrm{kN}$ load cell, applying a displacement rate of $100 \mathrm{~mm} / \mathrm{min}$ and a preload of 0,5 N. Deformation was measured using a long-stroke extensometer.

X-ray diffraction (XRD) was performed on rubber compounds with $35 \mathrm{phr}$ of SPR or N990, stretched up to various strains, in order to study the influence of the microalgal biomass and carbon black on the strain induced crystallization (SIC) behaviour of natural rubber. Compound NR 0 (with no filler) was subjected to strains equal to $250 \%$ and $450 \%$ and used as benchmark; NR SPR 35 and NR N990 35 were subjected to strains equal to $200 \%$ and $300 \%$. After being elongated using a Instron 5967 dynamometer, with a strain rate equal to $10 \mathrm{~mm} / \mathrm{min}$, samples were clamped on a support able to keep the strain constant, and they were successively scanned by $\mathrm{X}$-rays. Tests were performed with a scanning angle ranging from 15 to $40^{\circ}$, with steps of $0,02^{\circ}$ and a step time equal to $4 \mathrm{~s}$, by D8 Advance Brukel instrument characterized by a radiation emitted at $40 \mathrm{kV}, 40 \mathrm{~mA}$ and wavelength at $\lambda=1,5406 \AA$.

Diffractograms obtained were used to compute the crystallization index $\left(\chi_{c}\right)$ for each rubber compound, at each elongation, as a function of the draw ratio $\lambda$ defined as:

$$
\lambda=\frac{L}{L_{0}}=1+\varepsilon
$$

in which $\mathrm{L}_{0}$ is the initial length, $\mathrm{L}$ is the length of the deformed sample and $\varepsilon$ is the engineering strain.

Cristallinity index $\chi_{c}$ was evaluated dividing the area of the crystalline related peak by the whole area under the diffractogram line:

$$
\chi_{\mathrm{c}}(\%)=\frac{A_{\text {peak }}}{A_{\text {total }}} * 100
$$

Fracture tests were carried out adopting the pure shear test configuration, shown in Fig. 2. A notch of initial length $\mathrm{a}_{0}=15 \mathrm{~mm}$ was introduced via die-assisted razor blade sliding. Tests were performed loading the specimens on an Instron 5967 dynamometer, at the displacement rate of $50 \mathrm{~mm} / \mathrm{min}$. To allow the determination

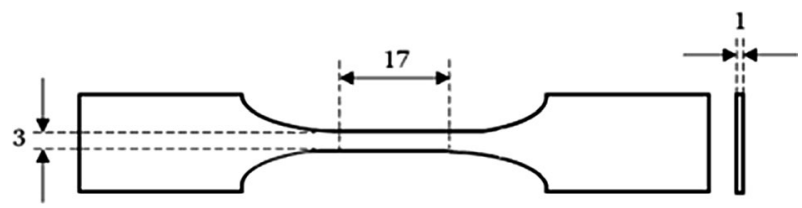

Fig. 1 Dumbbell specimen used in tensile tests. Dimensions are expressed in $\mathrm{mm}$ 


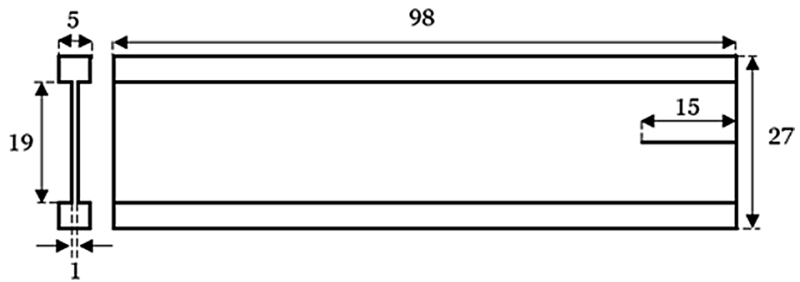

Fig. 2 Specimen used in pure shear fracture tests. Dimensions are expressed in $\mathrm{mm}$

of crack initiation by visual means, tests were recorded at $10 \mathrm{fps}$ with a 10 MPixel $\mu$ Eye UI5490 SE camera.

The fracture behaviour was described evaluating the J-integral at crack initiation [24]. For the pure shear geometry considered in this work, this parameter can be determined as:

$$
J_{\mathrm{i}}=\frac{U_{i}}{B\left(W-a_{0}\right)}
$$

in which $U_{i}$ is the input energy at fracture onset, corresponding to the area under the load-displacement curve up to crack initiation, $B$ and $W$ are the specimen thickness and width respectively and $a_{0}$ is the initial notch length [25].

\section{Results and discussion}

\section{SEM of microalgal biomass}

SEM on microalgal biomasses were performed in order to assess their size, shape and surface appearance after milling procedure. Imagines obtained for SPI and SPR are reported in Fig. 3, at different magnifications, and demonstrate that ball milling was effective in breaking the microalgal cell walls and in reducing the aggregates dimensions. Most of SPI and SPR granules measure few microns, ranging from 2 to $10 \mu \mathrm{m}$, and show an irregular and jagged surface. This characteristic could lead to an enhancement of the effective contact area between the filler and the rubber matrix, favouring their interaction.

\section{Rubbers processing}

\section{Rubbers compounding}

During compounding, carried out in Brabender internal mixer in two steps, torque and stock temperature were measured as a function of time and recorded by a drive unit. In Table 3 the total mixing time, maximum torque and maximum 

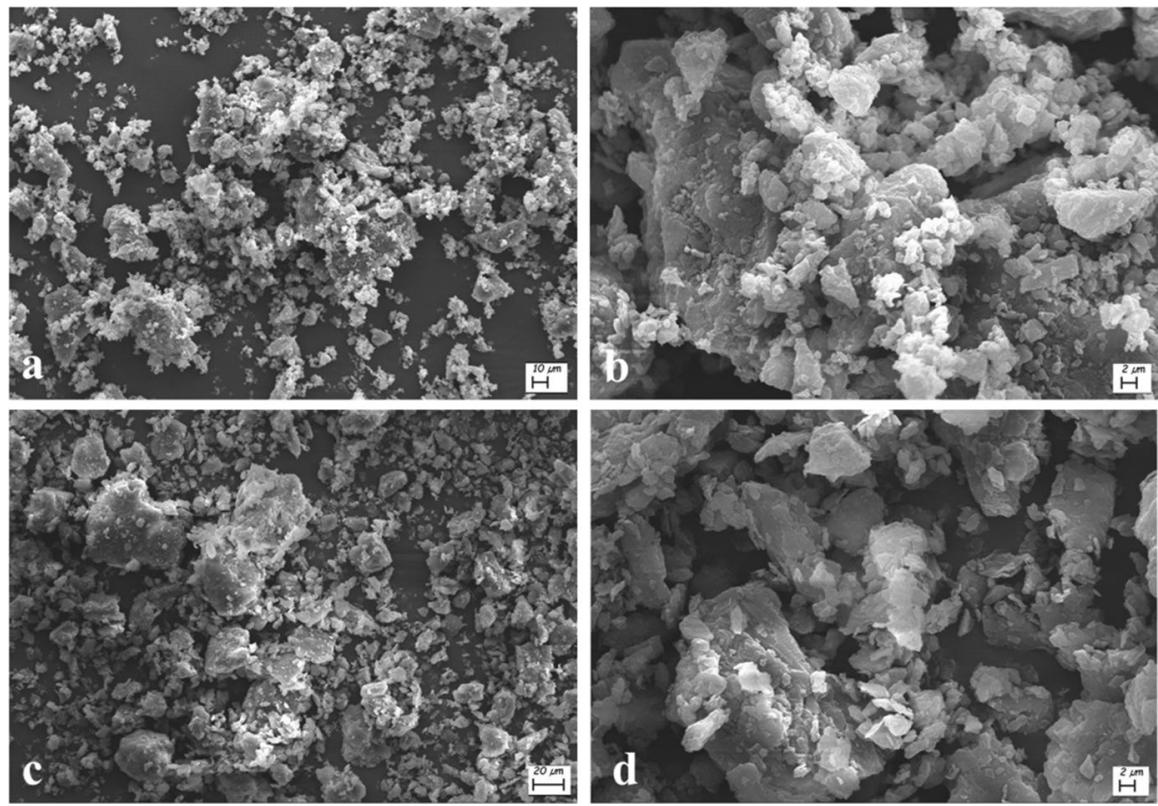

Fig. 3 SEM images of microalgal biomass after ball milling: a Spirulina $\times 1000$ b Spirulina $\times 5000$ c Spirulina residue $\times 1000$ d Spirulina residue $\times 5000$

Table 3 Mixing time, maximum torque and maximum temperature achieved in compounding process of NR0, NR SPI 25-50, NRER SPI 25, NR SPR 25-50 and NR N990 25-50

\begin{tabular}{|c|c|c|c|c|c|}
\hline \multirow[t]{2}{*}{ Sample Code } & \multicolumn{2}{|l|}{ Step 1} & \multicolumn{2}{|l|}{ Step 2} & \multirow[b]{2}{*}{ Mix Time (min-s) } \\
\hline & $\begin{array}{l}\text { Max } \\
\text { Torque } \\
(\mathrm{Nm})\end{array}$ & Max Temp. $\left({ }^{\circ} \mathrm{C}\right)$ & $\begin{array}{l}\text { Max } \\
\text { Torque } \\
(\mathrm{Nm})\end{array}$ & Max Temp. $\left({ }^{\circ} \mathrm{C}\right)$ & \\
\hline NR 0 & 33.1 & 94.1 & - & - & $5^{\prime} 54^{\prime \prime}$ \\
\hline NR SPI 25 & 31.5 & 105.6 & 35.4 & 105.3 & $8^{\prime} 33^{\prime \prime}$ \\
\hline NR SPI 50 & 31.2 & 105.4 & 36.6 & 104.6 & $7^{\prime} 50^{\prime \prime}$ \\
\hline NRER SPI 25 & 36.0 & 106.7 & 37.6 & 105.3 & $8^{\prime} 38^{\prime \prime}$ \\
\hline NR SPR 25 & 32.3 & 109.4 & 39.0 & 109.5 & $13^{\prime} 30^{\prime \prime}$ \\
\hline NR SPR 50 & 32.1 & 109.4 & 36.1 & 98.9 & $12^{\prime} 12^{\prime \prime}$ \\
\hline NR N990 25 & 42.5 & 106.8 & 36.2 & 105.5 & $7^{\prime} 06^{\prime}$ \\
\hline NR N990 50 & 56.6 & 110.2 & 52.7 & 110.7 & $8^{\prime} 30^{\prime \prime}$ \\
\hline
\end{tabular}

temperature achieved in the first and in the second mixing step of some rubber compounds produced are reported.

In compounds with carbon black, torque markedly increases with N990 content. On the contrary, in compounds with microalgae, torque does not change very much or even decreases increasing the microalgal biomass content. 
Actually, the addition of carbon black to natural rubber leads to an increase of the internal friction phenomena during compounding, while the addition of microalgae in certain cases reduces it, probably due to lubrication caused by their fatty acids fraction [19].

NRER SPI 25, in which the matrix is a blend of NR and ER, shows somewhat higher values of maximum torque and maximum temperature compared to NR SPI 25. In fact, repeating units of ER are characterized by lower rotational freedom, reflecting in a higher viscosity compared to NR [26]. For this reason, the resistance opposed by epoxidized rubber to shear forces, during mixing, is higher, giving reason for improved torque and temperature measured.

\section{Rubbers vulcanization}

Rubber compounds were cold pressed and cut in discs to be examined by DMA, at $150{ }^{\circ} \mathrm{C}$, to determine their vulcanization time. Results of these tests are isothermal curves of storage modulus $\left(\mathrm{G}^{\prime}\right)$ as a function of time. Some of them are reported in Fig. 4.

The optimum vulcanization time $t_{90}$ was evaluated from DMA curve as the time at which $\mathrm{G}^{\prime}$ equals the $90 \%$ of $\mathrm{G}_{\text {max }}^{\prime}$, being the latter the maximum value of the shear storage modulus at $150{ }^{\circ} \mathrm{C}$ measured at the highest achievable crosslinking density. These two quantities are reported in Table 4 together with the value of the modulus after 30 min from the achievement of $\mathrm{G}_{\text {max }}^{\prime}, \mathrm{G}^{\prime}\left(\mathrm{t}_{\mathrm{a}}\right)$, and the relevant percentage decay, $\Delta \mathrm{G}^{\prime}{ }_{\text {dec }}$, evaluated between $\mathrm{G}_{\text {max }}^{\prime}$ and $\mathrm{G}^{\prime}\left(\mathrm{t}_{\mathrm{a}}\right)$.

As it can be observed from these data, the time required for vulcanization of compounds with SPI and SPR does not change significantly with the filler content. However, curing times of rubbers filled with the microalgal biomass are moderately lower compared to curing times of N990 compounds. This can be explained considering that microalgae contain proteins that, through their - $\mathrm{OH}$ groups, could react with accelerators and sulphur forming polysulphides intermediates, which accelerate the vulcanization process [27].
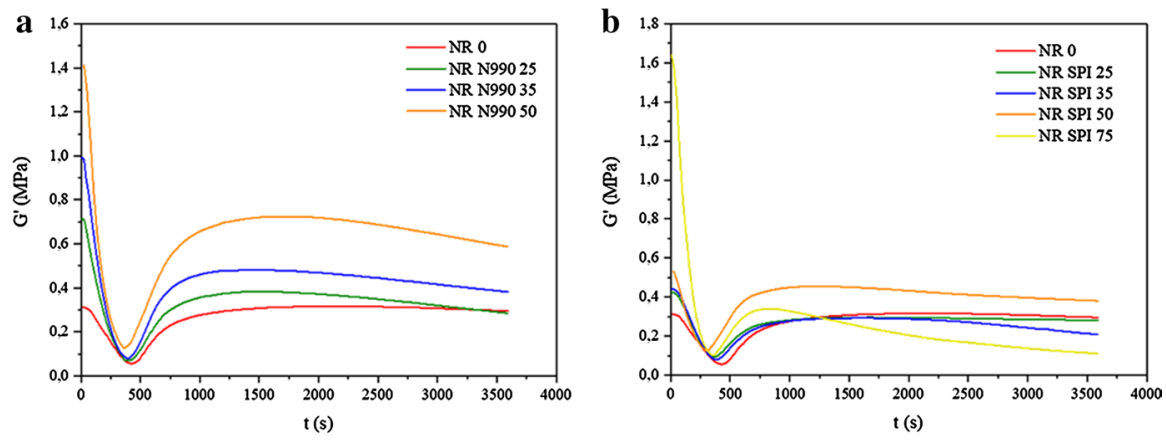

Fig. 4 Shear storage modulus $\mathrm{G}^{\prime}$ vs time at $150{ }^{\circ} \mathrm{C}$ and $1 \mathrm{~Hz}$ of a NR 0, NR N990 25-35-50 and b NR 0, NR SPI 25-35-50-75 
Table 4 Optimum curing time $\mathrm{t}_{90}$ and other characteristics measured during DMA tests

\begin{tabular}{lllll}
\hline Sample Code & $\mathrm{t}_{90}(\mathrm{~min})$ & $\mathrm{G}_{\max }^{\prime}(\mathrm{MPa})$ & $\mathrm{G}^{\prime}\left(\mathrm{t}_{\mathrm{a}}\right)(\mathrm{MPa})$ & $\Delta \mathrm{G}_{\mathrm{dec}}^{\prime}(\%)$ \\
\hline NR 0 & $18^{\prime} 01^{\prime}$ & 0.32 & 0.30 & 6.25 \\
NR SPI 25 & $13^{\prime} 31^{\prime \prime}$ & 0.30 & 0.28 & 6.67 \\
NR SPI 35 & $9^{\prime} 34^{\prime \prime}$ & 0.29 & 0.22 & 24.14 \\
NR SPI 50 & $11^{\prime} 30^{\prime \prime}$ & 0.46 & 0.40 & 13.04 \\
NR SPI 75 & $10^{\prime} 24^{\prime \prime}$ & 0.34 & 0.16 & 52.94 \\
NRER SPI 25 & $10^{\prime} 57^{\prime \prime}$ & 0.49 & 0.33 & 32.65 \\
NRER SPI 75 & $16^{\prime} 55^{\prime \prime}$ & 0.82 & 0.74 & 9.76 \\
NR SPR 25 & $11^{\prime} 16^{\prime \prime}$ & 0.36 & 0.21 & 41.67 \\
NR SPR 35 & $10^{\prime} 36^{\prime \prime}$ & 0.32 & 0.16 & 50.00 \\
NR SPR 50 & $10^{\prime} 15^{\prime \prime}$ & 0.27 & 0.12 & 55.56 \\
NR SPR 75 & $14^{\prime} 57^{\prime \prime}$ & 0.35 & 0.27 & 22.86 \\
NR N990 25 & $15^{\prime} 23^{\prime \prime}$ & 0.38 & 0.30 & 21.05 \\
NR N990 35 & $14^{\prime} 24^{\prime \prime}$ & 0.48 & 0.40 & 16.67 \\
NR N990 50 & $16^{\prime} 28^{\prime \prime}$ & 0.73 & 0.59 & 19.18 \\
\hline
\end{tabular}

On the other hand, $\mathrm{G}_{\max }^{\prime}$ of carbon black compounds increases with the filler loading, while $\mathrm{G}_{\max }^{\prime}$ of the microalgal biomass compounds does not change remarkably, and in some cases also decreases with the filler loading. This is not necessarily associated to a lower crosslinking density but, as already explained in "Rubbers compounding" section, can be related to the plasticization effect by fatty acids. The addition of epoxidized rubber to the matrix always improve $\mathrm{G}_{\text {max }}^{\prime}$, being ER normally characterized by a higher modulus compared to NR.

The percentage of modulus decay $\left(\Delta \mathrm{G}_{\mathrm{dec}}^{\prime}\right)$ was calculated to study the influence of each filler on the crosslinks stability at $150{ }^{\circ} \mathrm{C}$. SPR compounds and NR SPI 75 result less stable compared to N990 compounds $\left(\Delta \mathrm{G}^{\prime}{ }_{\mathrm{dec}}>40 \%\right)$, on the contrary, NR SPI 25 and 50 are more stable with respect to NR N990 25 and $50\left(\Delta \mathrm{G}_{\mathrm{dec}}^{\prime}<15 \%\right)$.

\section{Morphological characterization of rubber compounds}

SEM images in Figs. 5 and 6 show sections of cryofractured NR SPI 35 and NR SPR 35 surfaces, respectively. The microalgal biomass results finely dispersed in the matrix, and no particles detachment is found, indicating a good filler to rubber adhesion. More than SPR, SPI granules demonstrate a slightly higher tendency to aggregation. Etching was particularly efficient only for NR SPR 35. Probably, this is related to the higher solubility in water of SPR, which had already undergone disruptive treatments during procedure of proteins extraction. In this case, the etched matrix shows empty cavities from removed filler with an average size of $2-5 \mu \mathrm{m}$. 

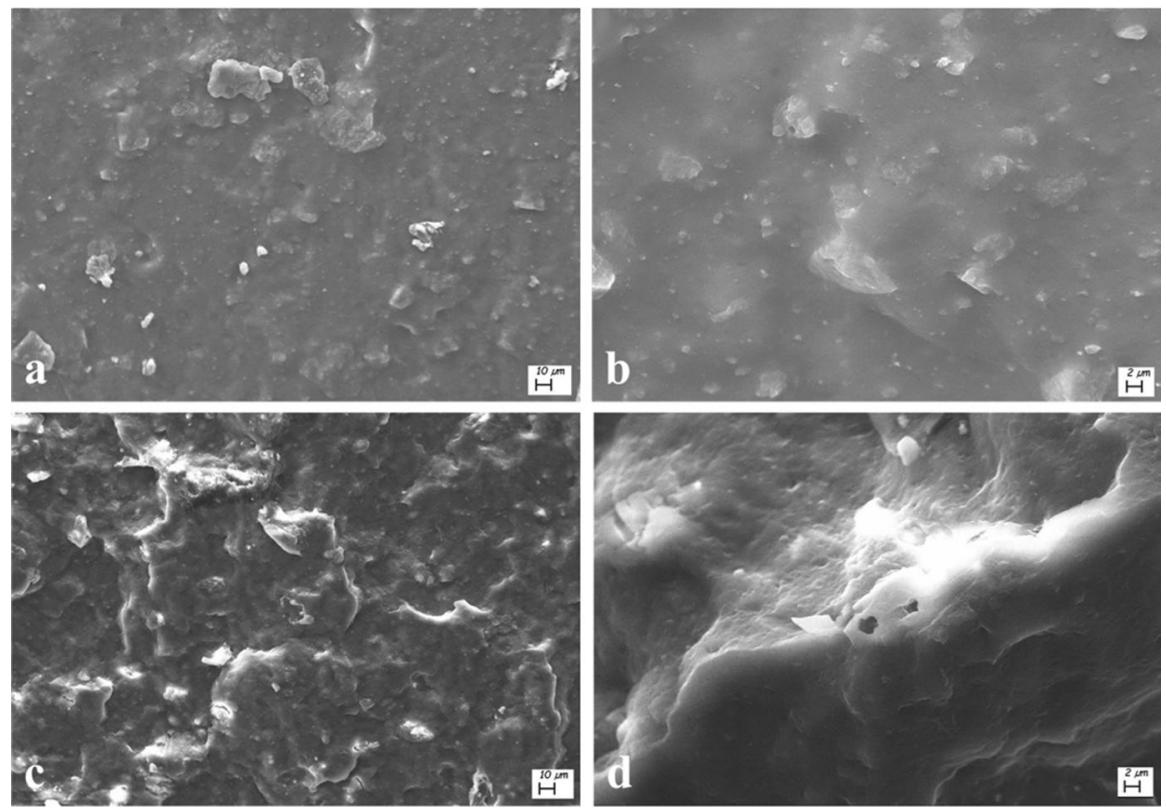

Fig. 5 SEM of a NR SPI $35 \times 1000$ b NR SPI $35 \times 5000 \mathbf{c}$ etched NR SPI $35 \times 1000 \mathbf{d}$ etched NR SPI $35 \times 5000$
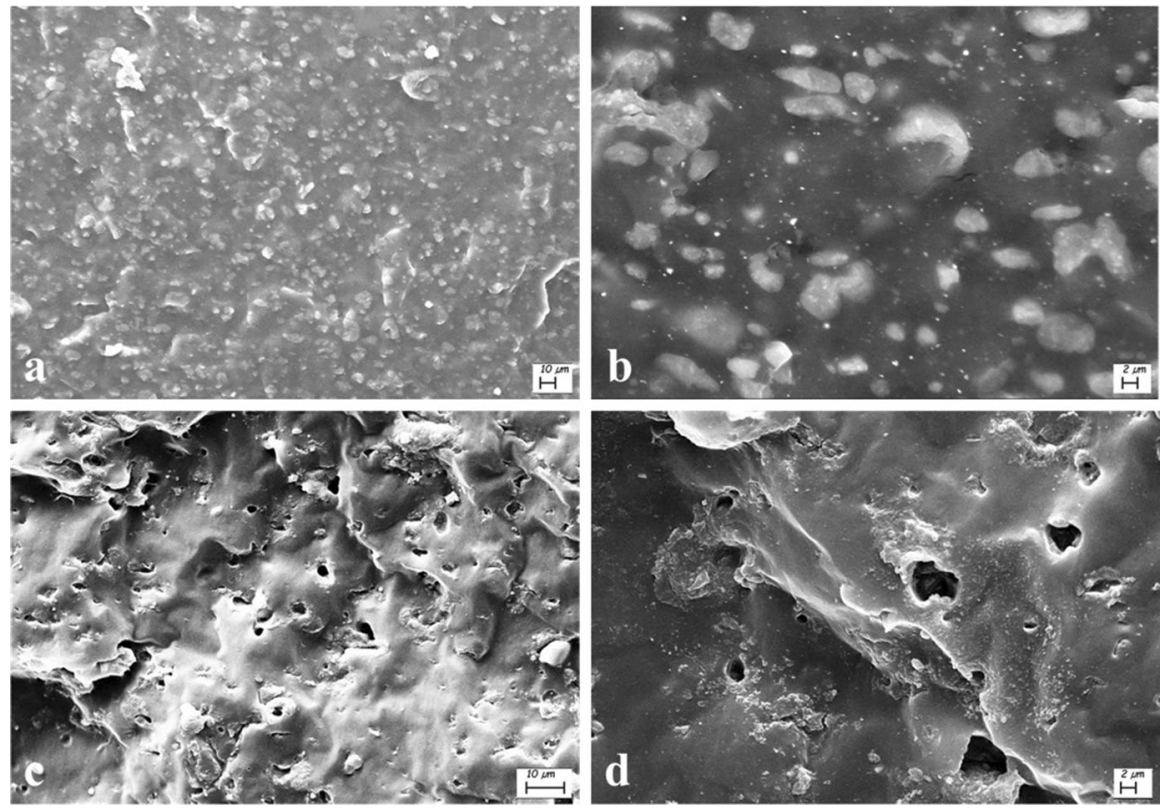

Fig. 6 SEM of a NR SPR $35 \times 1000$ b NR SPR $35 \times 5000$ c etched NR SPR $35 \times 2500$ d etched NR SPR $35 \times 5000$ 


\section{Thermal characterization of rubber compounds}

\section{Dynamic mechanical thermal analysis}

Dynamic mechanical thermal analysis (DMTA) were performed on NR 0, NR N990 35, NR SPI 35 and NR SPR 35 compounds. Relevant results, expressed in terms of shear storage modulus vs. temperature $\left(\mathrm{G}^{\prime}\right.$ vs. $\left.\mathrm{T}\right)$ and loss factor vs. temperature (tan $\delta$ vs. T) curves are reported in Fig. 7.

Below the glass transition temperature, $\mathrm{G}^{\prime}$ remains approximately constant, being the polymer in its glassy state. A modulus drop appears around $-40{ }^{\circ} \mathrm{C}$ in the glass transition zone. The modulus drop corresponds to an energy dissipation phenomenon displayed during the relaxation process, where the loss factor passes through a maximum. Then, the storage modulus reaches a plateau corresponding to the rubbery state $[3,8]$. At $25{ }^{\circ} \mathrm{C}$, the storage modulus improvement by $\mathrm{N} 990$ is $538 \%$ and by microalgal biomass is $183 \%$ for SPI and $235 \%$ for SPR in comparison with NR 0.

As shown in Fig. 7b, fillers have only a limited effect on the glass transition temperature: $\mathrm{N} 990$ leads to a $2{ }^{\circ} \mathrm{C}$ increase in natural rubber $\mathrm{Tg}$ (from -41 to $-39{ }^{\circ} \mathrm{C}$ ), while SPR and SPI decrease it by $1{ }^{\circ} \mathrm{C}\left(-42^{\circ} \mathrm{C}\right)$ and $2{ }^{\circ} \mathrm{C}\left(-43^{\circ} \mathrm{C}\right)$, respectively. The apparent $\mathrm{Tg}$ decrease by microalgal biomass addition is related to the increase of the polymer chain mobility, because of the microalgae fatty acids that generate a moderate plasticization effect [19], as previously mentioned.

Tan $\delta$ value (the height of the peak) shows a reduction in presence of the fillers N990, SPI and SPR, larger in the case of N990, indicating the restriction of movements of the rubber chains [7].

\section{Thermogravimetric analysis}

Thermal stability of rubber compounds filled with 35 phr of microalgal biomasses was assessed by means of TGA. In Fig. 8, weight percentage as a function of temperature is presented for each rubber compound analysed.
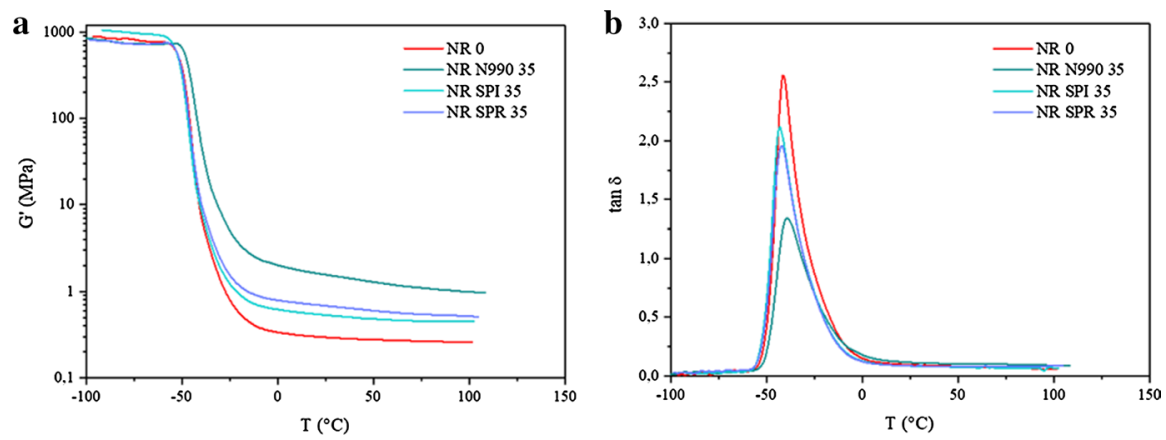

Fig. 7 a Shear storage modulus G' vs temperature and b loss factor tan $\delta$ vs temperature of NR 0, NR N990, NR SPI 35 and NR SPR 35 


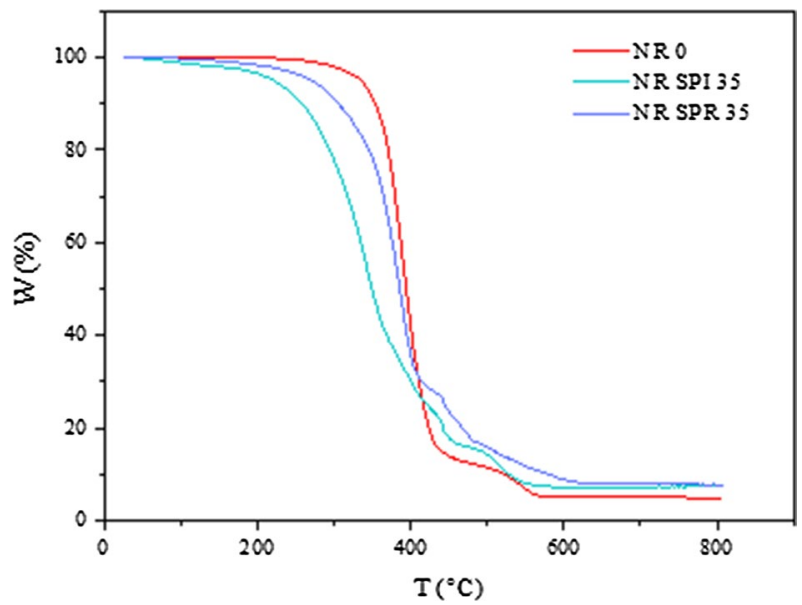

Fig. 8 TGA of NR 0, NR SPI 35 and NR SPR 35

Thermal decomposition of microalgae concerns loss of free and bound water in algae cells from room temperature up to $200{ }^{\circ} \mathrm{C}$ and devolatilization of carbohydrates, proteins and lipids from 200 to $600{ }^{\circ} \mathrm{C}[13,28]$.

Thermal degradation of natural rubber, instead, occurs mainly between 350 and $400{ }^{\circ} \mathrm{C}$ [29]. By consequence, the degradation of produced rubber compounds is characterized by a main degradation phenomenon, in correspondence with the temperature range in which rubber is expected to degrade, modulated by microalgae thermal decomposition within a wider temperatures range. TGA suggests that the compounds containing SPI and SPR are characterized by a lower thermal stability compared to natural rubber: the large amount of protein in microalgal biomass (especially in SPI) is responsible for the thermal degradation to start at temperature lower than $350{ }^{\circ} \mathrm{C}$, at which neat NR starts to degrade.

Temperatures at which $2 \%, 5 \%$ and $10 \%$ of material weight is lost and the final residual weight for each compound are reported in Table 5.

Data confirmed that the introduction of the microalgal biomasses lead to a decrease of the temperature required to a have a given mass loss. This reduction is, on average, of $89{ }^{\circ} \mathrm{C}$ and of $66^{\circ} \mathrm{C}$ for SPI and SPR compounds, respectively. Thermal degradation is practically completed at $600{ }^{\circ} \mathrm{C}$, and the final residue is higher when microalgal filler is present.

Table 5 Temperatures at which $2 \%, 5 \%$ and $10 \%$ of weight is lost and the final residual weight of NR 0, NR SPI 35 and NR SPR 35

\begin{tabular}{lllll}
\hline Sample code & $\mathrm{T}_{2 \%}\left({ }^{\circ} \mathrm{C}\right)$ & $\mathrm{T}_{5 \%}\left({ }^{\circ} \mathrm{C}\right)$ & $\mathrm{T}_{10 \%}\left({ }^{\circ} \mathrm{C}\right)$ & $\begin{array}{l}\text { Final resid- } \\
\text { ual weight } \\
(\%)\end{array}$ \\
\hline NR 0 & 298 & 335 & 353 & 4.7 \\
NR SPI 35 & 182 & 252 & 286 & 7.5 \\
NR SPR 35 & 213 & 270 & 305 & 7.8 \\
\hline
\end{tabular}




\section{Mechanical characterization of rubber compounds}

\section{Uniaxial tensile tests}

Vulcanized rubbers cut in dumbbell-shaped specimens were subjected to uniaxial tensile tests. Examples of tensile stress-strain curves are reported in Fig. 9. Modulus values at 100\% (E100), 200\% (E200), 300\% (E300) of strain, stress at break $\left(\sigma_{\mathrm{b}}\right)$ and strain at break $\left(\varepsilon_{\mathrm{b}}\right)$ for each rubber compound are summarized in Table 6.

As expected, N990 improves natural rubber modulus and stress at break, while reduces the strain at break.

In particular, modulus increases increasing N990 content, instead, strain at break and stress at break decrease increasing N990 content.

SPI and SPR act on natural rubber - similarly to carbon black N990 - as semireinforcing fillers, improving the compound stiffness and strength and reducing its maximum elongation. As for N990, increasing the content of SPI or SPR leads to a consequent decrease of strength and maximum elongation, and to an increase in modulus.

On average, with carbon black, rubber strength is slightly higher, while the microalgal biomass allows for larger deformations. For example, with $35 \mathrm{phr}$ of filler, NR N990 is characterized by a strength of $18.8 \mathrm{MPa}$ and a strain at break of $467.3 \%$; NR SPR has a strength of $16.8 \mathrm{MPa}$ and strain at break of $572.2 \%$. Reinforcement
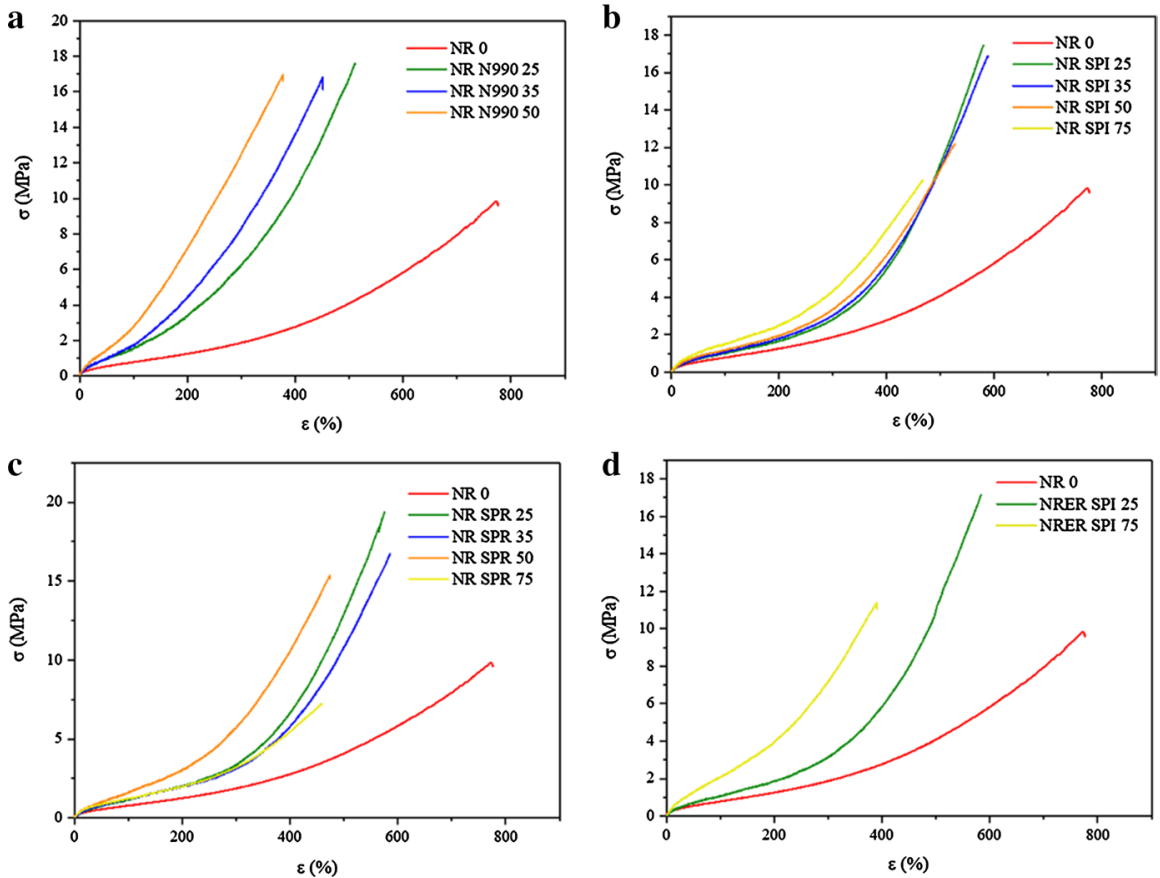

Fig. 9 Stress-strain curves of a NR 0, NR N990 25-35-50, b NR 0, NR SPI 25-35-50-75, c NR0, NR SPR 25-35-50-75 and $\mathbf{c}$ NR0, NRER SPI 25-75 
Table 6 Modulus values at $100 \%, 200 \%, 300 \%$ of strain, stress at break $\sigma_{\mathrm{b}}$ and strain at break $\varepsilon_{\mathrm{b}}$ of all rubber compounds

\begin{tabular}{llllll}
\hline Sample Code & E100 $(\mathrm{MPa})$ & E200 $(\mathrm{MPa})$ & E300 $(\mathrm{MPa})$ & $\sigma_{\mathrm{b}}(\mathrm{MPa})$ & $\varepsilon_{\mathrm{b}}(\%)$ \\
\hline NR 0 & $0.8 \pm 0.1$ & $0.6 \pm 0.1$ & $0.6 \pm 0.1$ & $11.2 \pm 1.0$ & $787.7 \pm 13.2$ \\
NR SPI 25 & $0.9 \pm 0.2$ & $0.8 \pm 0.1$ & $0.9 \pm 0.1$ & $16.4 \pm 1.3$ & $567.2 \pm 15.7$ \\
NR SPI 35 & $1.1 \pm 0.1$ & $0.9 \pm 0.1$ & $1.0 \pm 0.1$ & $15.9 \pm 0.9$ & $572.3 \pm 15.6$ \\
NR SPI 50 & $1.2 \pm 0.1$ & $1.0 \pm 0.1$ & $1.1 \pm 0.1$ & $11.9 \pm 0.4$ & $525.5 \pm 7.6$ \\
NR SPI 75 & $1.6 \pm 0.1$ & $1.3 \pm 0.1$ & $1.5 \pm 0.2$ & $9.9 \pm 1.7$ & $457.7 \pm 30.2$ \\
NRER SPI 25 & $1.1 \pm 0.1$ & $1.0 \pm 0.2$ & $1.2 \pm 0.2$ & $17.6 \pm 1.8$ & $612.0 \pm 38.1$ \\
NRER SPI 75 & $2.1 \pm 0.2$ & $2.0 \pm 0.2$ & $2.4 \pm 0.2$ & $10.1 \pm 2.2$ & $383.3 \pm 43.5$ \\
NR SPR 25 & $1.3 \pm 0.1$ & $1.1 \pm 0.1$ & $1.1 \pm 0.3$ & $17.9 \pm 3.6$ & $533.9 \pm 76.6$ \\
NR SPR 35 & $1.4 \pm 0.2$ & $1.2 \pm 0.3$ & $1.4 \pm 0.2$ & $16.8 \pm 3.3$ & $572.2 \pm 32.8$ \\
NR SPR 50 & $1.4 \pm 0.1$ & $1.3 \pm 0.1$ & $1.7 \pm 0.1$ & $12.9 \pm 2.5$ & $478.3 \pm 30.3$ \\
NR SPR 75 & $1.5 \pm 0.1$ & $1.4 \pm 0.1$ & $1.7 \pm 0.2$ & $7.5 \pm 0.4$ & $421.8 \pm 53.4$ \\
NR N990 25 & $1.5 \pm 0.1$ & $1.7 \pm 0.2$ & $2.1 \pm 0.2$ & $19.4 \pm 1.5$ & $523.4 \pm 20.2$ \\
NR N990 35 & $1.9 \pm 0.2$ & $2.4 \pm 0.2$ & $2.9 \pm 0.2$ & $18.8 \pm 2.3$ & $467.3 \pm 26.9$ \\
NR N990 50 & $2.8 \pm 0.1$ & $3.6 \pm 0.1$ & $4.2 \pm 0.1$ & $16.2 \pm 1.3$ & $361.6 \pm 17.4$ \\
\hline
\end{tabular}

effects can be observed up to $50 \mathrm{phr}$ of microalgal filler, while for SPI or SPR equal to $75 \mathrm{phr}$ strength becomes lower than that of unreinforced natural rubber (below 11.2 MPa).

Moduli measured at $100 \%, 200 \%$ and $300 \%$ of strain show that carbon black is responsible for higher stiffness and also major strain hardening with respect to microalgal biomass.

SPI and SPR, which granules are characterized by similar shape and size, exhibit comparable reinforcing properties, despite their difference in protein content.

An attempt to improve the mechanical properties of NR filled with the microalgal biomass was done adding ER to the compound, to increase the matrix-filler affinity due to possible polar interactions among the epoxy group of rubber and the various nucleophilic functions contained in microalgae. Actually, SPI is hydrophilic and polar, and ER swells in presence of a polar solvent [26]. Data obtained from the 25 phr compound, when SPI has a reinforcing effect, seems to confirm this hypothesis, being both the tensile strength ant the strain at break slightly higher for the compound containing ER; on the other hand, no significant effect is observed in the value of the moduli.

\section{Strain induced crystallization behaviour}

X-ray diffraction was performed to evaluate how the presence of the microalgal filler, in comparison with carbon black, affects the ability of natural rubber to crystallize under strain. Crystalline cell of natural rubber is expected to generate a peak at $\theta=21^{\circ}$, in correspondence with the crystallographic plane (120). The literature reports that the onset of SIC for natural rubber occurs for strain around $300 \%$. Typically, when carbon black is added, the strain at which the onset of SIC occurs is 
supposed to decrease by an amount which depends on the filler content. Carbon black, in fact, leads to a local strain amplification in the rubber matrix, making the nucleation of crystallites easier [30, 31].

In Fig. 10a an example of diffractogram obtained by XRD analysis of NR SPR 35 and NR N990 35 strained at 300\% is reported, while in Fig. 10b crystallinity index $\chi_{c}$ was plotted as a function of the draw ratio $\lambda$, for each rubber compound, at each strain condition tested.

As reported in literature, NR 0 does not crystallize at $\lambda=3.5$ but shows crystallization peak at $\lambda=5.5$. As already known for carbon black, also the introduction of the microalgal filler causes a decrease of the overall strain required to observe SIC in natural rubber. In fact, both compounds already crystallize at $\lambda=3$, with the crystallites content that increases with the draw ratio. At draw ratio equal to 3, NR N990 35 and NR SPR 35 are characterized by a similar crystallinity index of about $6 \%$ and $5 \%$, respectively; at draw ratio equals to 4 their crystallinity index increases to about $7 \%$ and $6 \%$, respectively.

\section{Pure shear fracture test}

Figs. 11a-b report the load displacement curves obtained during the fracture tests and the relevant dependence of the applied J-integral as a function of the displacement, respectively. In both plots, the full dots indicate the fracture onset. In pure shear fracture tests, the J-integral was evaluated at crack initiation to obtain some information regarding the fracture behaviour of NR 0, NR N990 35 and NR SPR 35 compounds.

As already observed during the tensile tests and as expected, filled compounds are characterized by a higher stiffness. The slightly higher stiffness of NR SPR 35 with respect to NR N990 35, in contrast with the result obtained by tensile tests, may be related to small discrepancies in the production processes employed to produce the different specimens.

Figure 11c shows that the addition of the filler causes a decrease of the J-integral with respect to the values measured for the unfilled natural rubber NR 0 , as found in a previous study for low filler content rubbers [25]. Both CB N990 and SPR act
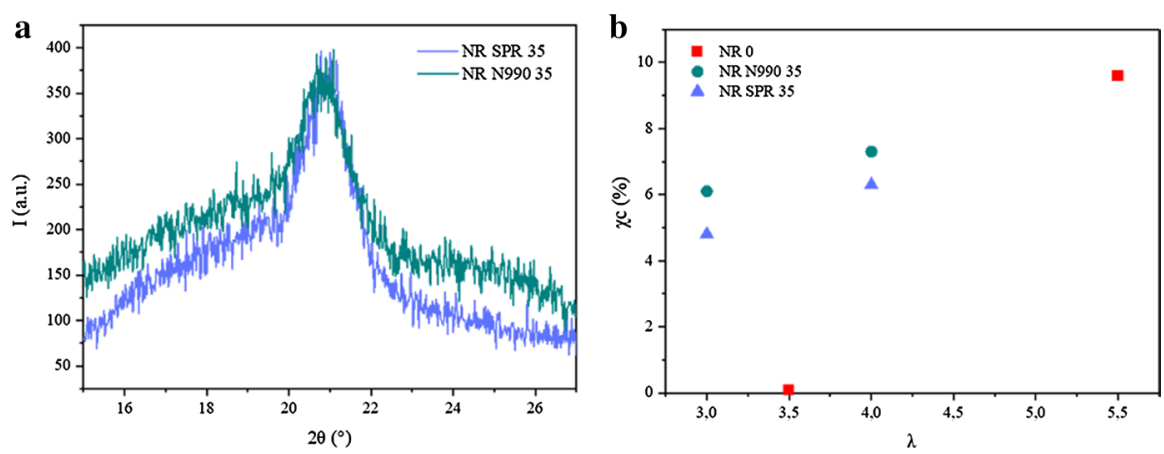

Fig. 10 a XRD of NR SPR 35 and NR N990 35 strained at 300\% and b crystallinity index as a function of draw ratio of NR 0, NR N990 35 and NR SPR 35 

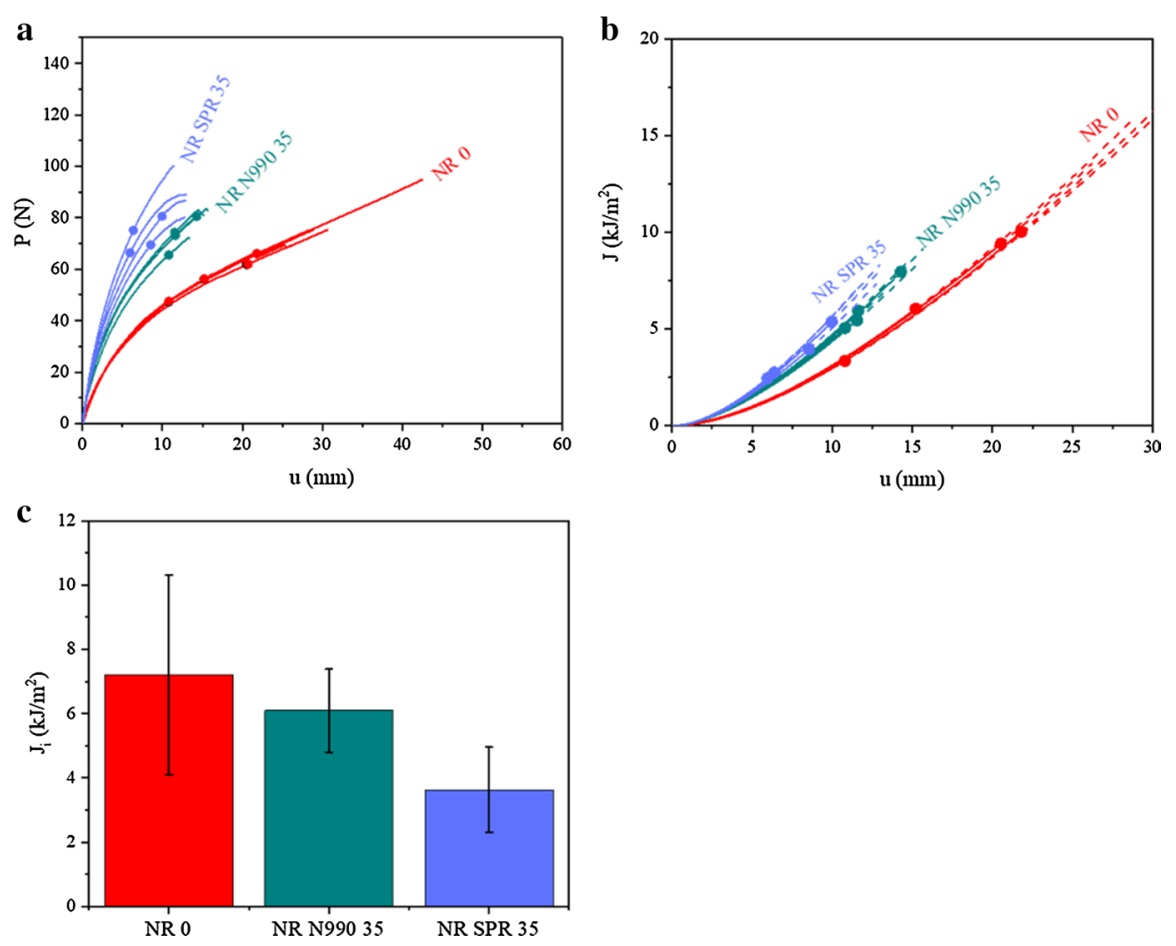

Fig. 11 a Force vs. displacement measured during pure shear fracture tests. Dots represent the onset of crack propagation $\mathbf{b}$ J-integral vs. displacement $\mathbf{c}$ energy fracture parameter of NR 0, NR SPR 35 and NR N990 35

primarily as heterogeneities, favouring the crack initiation; this behaviour is more accentuated for NR SPR 35. It could be assumed that, probably due to particles size and structure, failure occurs at strains lower than those required to have SIC at the crack tip, a phenomenon that would have enhanced the resistance to crack onset [25].

\section{Environmental impact of microalgal biomass and carbon black}

In this final section, some considerations concerning the environmental impact of microalgal biomass and carbon black are made. The functional unit referred to is $1 \mathrm{~kg}$ of filler produced for CB and $1 \mathrm{~kg}$ of dry biomass obtained for SPI. Table 7 reports the global warming power (GWP) in terms of kilograms of equivalent $\mathrm{CO}_{2}$ emitted and the energy demand per functional unit. Data given for CB are from Cabot Corporation sustainability report (2019) [32], while indicative data for Spirulina are obtained from the literature [33].

Evidently, Spirulina cultivation shows lower environmental impact compared to $\mathrm{CB}$ production. Spirulina is a cyanobacteria able to fix $\mathrm{CO}_{2}$ from air by photosynthetic mechanism, thus reducing carbon dioxide emission. It is estimated that $1 \mathrm{~kg}$ 
Table 7 Global warming power (GWP) and energy demand per functional unit

\begin{tabular}{lll}
\hline & $\begin{array}{l}\mathrm{GWP} \\
\left(\mathrm{kg} \mathrm{CO}_{2 \mathrm{eq}}\right)\end{array}$ & $\begin{array}{l}\text { Energy } \\
(\mathrm{MJ})\end{array}$ \\
\hline Carbon Black & 2.26 & 60.87 \\
Spirulina & $-0.11^{*}$ & $27.60^{* *}$ \\
\hline
\end{tabular}

*Harvesting and drying are not included

**Anaerobic digestion (required for biogas production) is also included

of Spirulina absorbs $1,72 \mathrm{~kg}$ of equivalent $\mathrm{CO}_{2}$. This explains why microalgae turn out to be carbon neutral, or even exhibit a negative value in GWP category. Rodriguez et al. reported that nutrients production has the largest influence on GWP. Using nutrients contained in wastewater, as it was actually done for the microalgal biomass employed in this study, would furtherly decrease this contribution [33]. It is to underline, however, that data reported for GWP only concerns microalgae cultivation and does not include harvesting and drying procedures, required to obtain lyophilized biomass usable as material filler, and whose impact will depend on the technologies employed.

Microalgal biomass is less wasteful than carbon black also in terms of energy demand. Data show around $30 \mathrm{MJ}$ of additional energy for carbon black production compared to Spirulina cultivation, per functional unit [32, 33]. This difference would be even higher considering that Rodriguez et al. reported value also including Spirulina anaerobic digestion, required in case of biogas production but not in case of filler obtainment. An additional contribution must be considered, also in this category, owed to harvesting and further drying necessary for filler production.

Since the carbon black production process is nowadays widely known and developed while microalgae cultivation exploiting wastewater treatments is a relatively new technology to be optimised and intensified on a larger scale, the use of microalgal biomass as filler could lead to very promising results in mitigating the environmental impact related to rubber compounds production and disposal.

\section{Conclusions}

In this work, Spirulina biomass (SPI) and its low protein content fraction (SPR) were employed as fillers in natural rubber compounds. SEM images showed their good adhesion and dispersion within the matrix. The microalgal biomass was able to reduce rubber curing time compared to carbon black N990 (CB N990). From a thermal point of view, microalgae worsen the thermal stability of NR while, in terms of mechanical properties, microalgal particles, up to $50 \mathrm{phr}$, acted similarly to a semireinforcing filler, moderately increasing NR strength (by a maximum of $5 \mathrm{MPa}$ ) and modulus. Overall, compared to N990, SPI and SPR allow for slightly lower strength and larger deformations. Moreover, the addition of ER to rubber matrix ensured its higher interaction with the polar nature of Spirulina, improving the tensile strength and the maximum allowable strain. It was observed that unreinforced rubber was 
characterized by higher fracture toughness compared to rubber filled with both CB N990 and the microalgal biomass at 35 phr. Interestingly, XRD showed that the effect of the microalgal filler on strain induced crystallization behaviour of natural rubber is comparable to that of CB N990.

The results of this study demonstrate that dry Spirulina biomass and its fraction can be effectively used as biofillers to obtain performant natural rubber compounds with the advantage of providing a better environmental profile compared to carbon black, valorising the biomass within a perspective of circular economy.

Acknowledgements The authors wish to thank Archimede Ricerche (Dr. S. Mangini) and Extractis (Dury, France) for the supply of the microalgal biomasses.

Funding Open access funding provided by Politecnico di Milano within the CRUI-CARE Agreement. This work has received funding from SaltGae project (part of European Union's Horizon 2020 research and innovation program) and Wast4Bioplast project (by Cariplo Foundation).

\section{Declarations}

Conflict of interest The authors declare that they have no conflict of interest.

Open Access This article is licensed under a Creative Commons Attribution 4.0 International License, which permits use, sharing, adaptation, distribution and reproduction in any medium or format, as long as you give appropriate credit to the original author(s) and the source, provide a link to the Creative Commons licence, and indicate if changes were made. The images or other third party material in this article are included in the article's Creative Commons licence, unless indicated otherwise in a credit line to the material. If material is not included in the article's Creative Commons licence and your intended use is not permitted by statutory regulation or exceeds the permitted use, you will need to obtain permission directly from the copyright holder. To view a copy of this licence, visit http://creativecommons.org/licen ses/by/4.0/.

\section{References}

1. Mooibroek H, Cornish K (2000) Alternative sources of natural rubber. Appl Microbiol Biotechnol 53:355-365. https://doi.org/10.1007/s002530051627

2. Rattanasom N, Saowapark T, Deeprasertkul C (2007) Reinforcement of natural rubber with silica/ carbon black hybrid filler. Polym Testing 26:369-377. https://doi.org/10.1016/j.polymertesting. 2006.12.003

3. Visakh PM, Thomas S, Oksman K, Mathew AP (2012) Crosslinked natural rubber nanocomposites reinforced with cellulose whiskers isolated from bamboo waste: Processing and mechanical/thermal properties. Compos A Appl Sci Manuf 43:735-741. https://doi.org/10.1016/j.compositesa.2011.12. 015

4. Erman B, Mark J, Roland M (2013) The science and technology of rubber. Elsevier

5. Donnet J-B, Bansal RC, Wang M-J (1993) Carbon black: Science and technology. Marcel Dekker Inc, New York

6. Ooi ZX, Ismail H, Bakar AA (2013) Optimisation of oil palm ash as reinforcement in natural rubber vulcanisation: a comparison between silica and carbon black fillers. Polym Testing 32:625-630. https://doi.org/10.1016/j.polymertesting.2013.02.007

7. Ikeda Y, Phakkeeree T, Junkong P et al (2017) Reinforcing biofiller "lignin" for high performance green natural rubber nanocomposites. RSC Adv 7:5222-5231. https://doi.org/10.1039/c6ra26359c 
8. Angellier H, Molina-Boisseau S, Dufresne A (2005) Mechanical properties of waxy maize starch nanocrystal reinforced natural rubber. Macromolecules 38:9161-9170. https://doi.org/10.1021/ ma0512399

9. Ismail H, Shaari SM, Othman N (2011) The effect of chitosan loading on the curing characteristics, mechanical and morphological properties of chitosan-filled natural rubber (NR), epoxidised natural rubber (ENR) and styrene-butadiene rubber (SBR) compounds. Polym Testing 30:784-790. https:// doi.org/10.1016/j.polymertesting.2011.07.003

10. Rizwan M, Mujtaba G, Memon SA et al (2018) Exploring the potential of microalgae for new biotechnology applications and beyond: a review. Renew Sustain Energy Rev 92:394-404. https://doi. org/10.1016/j.rser.2018.04.034

11. Mata TM, Martins AA, Caetano NS (2010) Microalgae for biodiesel production and other applications: a review. Renew Sustain Energy Rev 14:217-232. https://doi.org/10.1016/j.rser.2009.07.020

12. Satyanarayana AG, Mariano AB, Vargas JVC (2011) A review on microalgae, a versatile source for sustainable energy and materials. Int J Energy Res 35:291-311. https://doi.org/10.1002/er.1695

13. Zeller MA, Hunt R, Jones A, Sharma S (2013) Bioplastics and their thermoplastic blends from Spirulina and Chlorella microalgae. J Appl Polym Sci 130:3263-3275. https://doi.org/10.1002/app. 39559

14. Torres S, Navia R, Murdy RC et al (2015) Green composites from residual microalgae biomass and poly(butylene adipate-co-terephthalate): processing and plasticization. ACS Sustainable Chemistry and Engineering 3:614-624. https://doi.org/10.1021/sc500753h

15. Cinar SO, Chong ZK, Kucuker MA et al (2020) Bioplastic production from microalgae: A review. Int J Environ Res Public Health 17:1-21. https://doi.org/10.3390/ijerph17113842

16. Bulota M, Budtova T (2015) PLA/algae composites: morphology and mechanical properties. Compos A Appl Sci Manuf 73:109-115. https://doi.org/10.1016/j.compositesa.2015.03.001

17. Batista AP, Nunes MC, Raymundo A et al (2011) Microalgae biomass interaction in biopolymer gelled systems. Food Hydrocolloids 25:817-825. https://doi.org/10.1016/j.foodhyd.2010.09.018

18. Ciapponi R, Turri S, Levi M (2019) Mechanical reinforcement by microalgal biofiller in novel thermoplastic biocompounds from plasticized gluten. Materials 12:1-11. https://doi.org/10.3390/ma120 91476

19. Głowińska E, Datta J, Parcheta P, Kaźmierczak N (2018) Novel approaches of using of Spirulina Platensis in natural rubber based composites. Journal of Renewable Materials 6:680-687

20. Abdel-Raouf N, Al-Homaidan AA, Ibraheem IBM (2012) Microalgae and wastewater treatment. Saudi Journal of Biological Sciences 19:257-275. https://doi.org/10.1016/j.sjbs.2012.04.005

21. Beuckels A, Smolders E, Muylaert K (2015) Nitrogen availability influences phosphorus removal in microalgae-based wastewater treatment. Water Research Water Research 77:98-106. https://doi.org/ 10.1016/j.watres.2015.03.018

22. Onyshchenko E, Blandin G, Comas J, Dvoretsky A (2020) Influence of microalgae wastewater treatment culturing conditions on forward osmosis concentration process. Environ Sci Pollut Res 27:1234-1245. https://doi.org/10.1007/s11356-018-3607-5

23. Gray N (2008) Biology of wastewater treatment. Imperial College Press, London

24. Zhu XK, Joyce JA (2012) Review of fracture toughness (G, K, J, CTOD, CTOA) testing and standardization. Eng Fract Mech 85:1-46. https://doi.org/10.1016/j.engfracmech.2012.02.001

25. Marano C, Boggio M, Cazzoni E, Rink M (2014) Fracture phenomenology and toughness of filled natural rubber compounds via the pure shear test specimen. Rubber Chem Technol 87:501-515. https://doi.org/10.5254/rct.14.86950

26. Burfield DR, Lim K-L, Law K-S (1984) Epoxidation of natural rubber latices: methods of preparation and properties of modified rubbers. J Appl Polym Sci 29:1661-1673. https://doi.org/10.1002/ app.1984.070290520

27. Wei YC, Liu GX, Zhang HF et al (2019) Non-rubber components tuning mechanical properties of natural rubber from vulcanization kinetics. Polymer 183:121911. https://doi.org/10.1016/j.polymer. 2019.121911

28. Bach QV, Chen WH (2017) Pyrolysis characteristics and kinetics of microalgae via thermogravimetric analysis (TGA): a state-of-the-art review. Biores Technol 246:88-100. https://doi.org/10. 1016/j.biortech.2017.06.087

29. Yahya YSR, Azura AR, Ahmad Z (2011) Effect of curing systems on thermal degradation behaviour of natural rubber (SMR CV 60). J Phys Sci 22:1-14

30. Huneau B (2011) Strain-induced crystallization of natural rubber: a review of X-ray diffraction investigations. Rubber Chem Technol 84:425-452. https://doi.org/10.5254/1.3601131 
31. Toki S, Fujimaki T, Okuyama M (2000) Strain-induced crystallization of natural rubber as detected real-time by wide-angle X-ray diffraction technique. Polymer 41:5423-5429. https://doi.org/10. 1016/S0032-3861(99)00724-7

32. Sustainability report (2019) Cabot Corporation. https://www.cabotcorp.com/responsibility/ourcommitment/sustainability-resources. Accessed 20 January 2021.

33. Rodríguez R, Espada JJ, Moreno J et al (2018) Environmental analysis of Spirulina cultivation and biogas production using experimental and simulation approach. Renewable Energy 129:724-732. https://doi.org/10.1016/j.renene.2017.05.076

Publisher's Note Springer Nature remains neutral with regard to jurisdictional claims in published maps and institutional affiliations. 